\title{
Putting AI to Work in Geoscience
}

\section{by Susan M. Yatabe and Andrea G. Fabbri}

\begin{abstract}
Scientists in research and industrial facilities are now becoming increasingly involved in the study of artificial intelligence (AI), in which computer systems are being designed to emulate human behaviour. This article reviews the recent use of AI techniques in such diverse geoscience problems as the modelling of geological processes, the prediction of mineral and petroleum deposits, reasoning in more than one dimension, and the interpretation of typical data from geophysical surveys. Some 37 expert systems used in geology are analyzed and described. (Ed.)
\end{abstract}

\section{Introduction}

Artificial intelligence, or $\mathrm{AI}$, is a field of computer science that strives to design machines to imitate human behaviour and intelligence. AI computer programs differ from traditional ones in their ability to manipulate data and logical inferences as well as to solve problems in a symbolic manner, as opposed to an algorithmic and purely quantitative manner. AI programs commonly accept data that may be incomplete, ambiguous or uncertain. Scientists have been involved in Al research for over 30 years, but it is only in the past decade or so that these computing methods have been applied to actual problems and that commercial $\mathrm{Al}$ products have become available.

Al encompasses four broad and often overlapping areas: natural language understanding, machine learning, computer (or machine) vision, and expert systems (Waterman, 1986). Certainly the most rapidly expanding, well-publicized and controversial of these is the field of expert systems - the design and implementation of computer programs that set out to rival the problem-solving ability of human experts in specific fields (Fig. 1). The application of these new techniques to geoscience is described here, the man-machine interface and computational aspects of $\mathrm{Al}$ being described elsewhere (Yatabe and Fabbri, 1988).

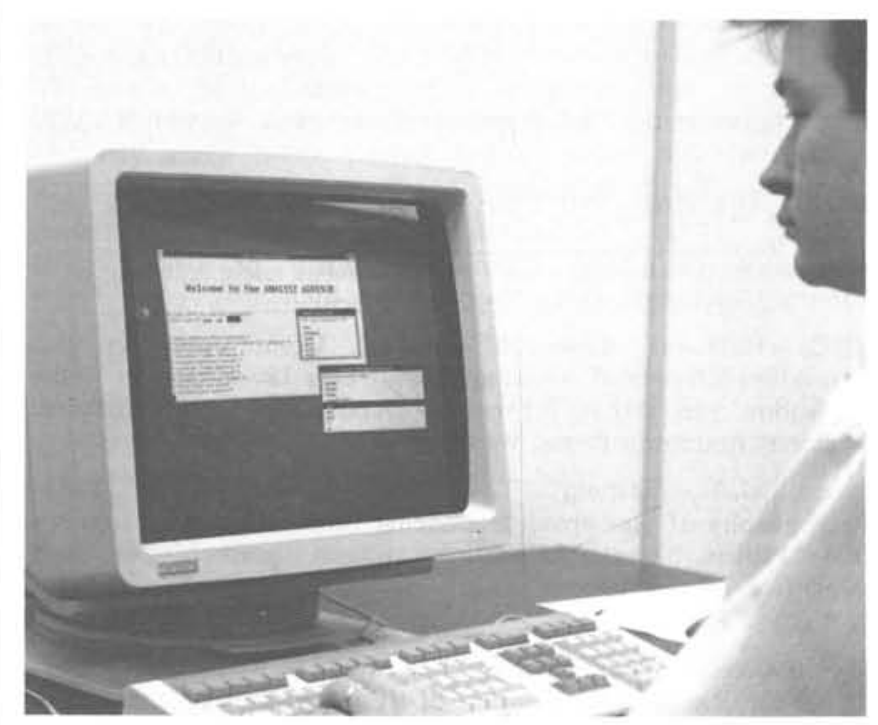

Figure 1: A micro VAX-based workstation used at the Canada Centre for Remote Sensing to develop expert systems for image processing. See Goodenough et al. 1987.
AI research has recently been experiencing financial and technical difficulties, possibly due to unrealistic expectations of what can be achieved. Much of the available literature is of a general and preliminary nature, but the geological requirements for automated reasoning are beginning to surface. Despite the problems in applying AI to geology, such as the difficulty in translating the geological knowledge into a computational form, positive trends ean be recognized. Many disciplines of the geosciences are becoming involved in AI research, with a focus on representing imprecise and uncertain information, and on exploiting the spatial nature of geological data. The work is obviously aided by the ever increasing capability and availability of computers and the decreasing cost of personal computers.

\section{$\mathrm{AI}$ and Expert Systems}

In order to construct an expert system, the knowledge of the human expert must be transformed into computer code. This is usually done by a specialist called a "knowledge engineer." Acquiring the knowledge is a difficult, iterative process usually done through a series of interviews between experts and a knowledge engineer. Even though researchers are now seeking ways to acquire this knowledge in an automatic fashion, knowledge engineering is still a vital element in the process. The finished expert system carries out tasks involving, for example, reasoning, sequencing of tasks and explanations, and it can be used by a non-expert, who may request specific information on the current problem.

The structure of an expert system is organized in two separate parts, the knowledge base and the "inference engine." The former contains both facts and rules, whereas the latter controls the reasoning and sequencing mechanisms of the system and is typically generic to the task. It is subdivided into an interpreter, which makes logical inferences (applies the facts and/or rules) and a scheduler to sequence them. The interface between the expert system and the user can be a natural language, such as English, a graphic interactive tool, or other types of person-machine interaction.

There are several ways in which knowledge ean be represented in order to solve a problem. The simplest of these is based on rules of the form exemplified by Table 1 . These consist of an IF part (premise or condition) and a THEN part (a conclusion or action). Table 1 shows "production rules" of increasing complexity from I to $\mathrm{V}$. In rule $\mathrm{I}$, the premise consists of three parts, linked by "AND" relationships. In II, the conclusion consists of a list of values. Rule III has three parts in its premise, and the conclusion consists of four actions. In rule $\mathrm{IV}$, the conclusion has a weight to 1.0 for the presence of suggestive evidence. Some rules provide numerical values of probability or confidence. An example is number $V$ where one weight (20) is associated with the presence and another (1) with the absence of evidence, and an a priori probability associated with the hypothesis confirmed by the conclusion.

When related rules are linked together to make an inference, they form "inference networks," as in PROSPECTOR, one of the earliest expert systems developed (Duda et al., 1978, 1979 and Duda, 1980). These rules can be based on heuristics, or rules of thumb, which are short cuts that 
TABLE 1: Examples of rules from expert systems designed for geological applications.

\section{(I) Log analysis interpretation}

"IF the water fit is normal and the Rw quality is excellent and there are more than $10 \mathrm{ft}$ of hydrocarbons

THEN the hydrocarbon presence is significant" (Apté and Neiss, 1985 , p. 586 , ELAS).

\section{(II) Volcanological prediction}

"IF the preceding eruption dates from between 100 and 1000 years ago,

I'LEN the probabilities that the VEI (volcanic eruptivity index) are $0,1,2,3,4,5$ or 6 are $11,5,45,26,6,4$ and 1 g, respectively" (Rosenthal-Sabroux et al., 1984, p. 107).

\section{(III) Dipmeter test interpretation}

"IF there is a delta-dominated, continental-shelf marine zone, and there is a sand zone intersecting the marine zone, and there is a blue pattern within the intersection,

THEN assert a tributary fan zone: top = top of olue pattern; bottom = bottom of blue pattern; flow = azimuth of blue pattern" (Smith, 1984, p. 63; Dipmeter Advisor).

\section{(IV) Seismic event identification}

"IF (1) the focal depth of the event is deeper than $30 \mathrm{~km}$, and (2) the location of the event is within a populated area,

TIEN there is suggestive evidence (1.0) that the seismic event is an earthquake" (Liu, 1985, p. 461).

\section{(v) Mineral exploration}

"IF intrusive breccia, $\mathrm{R} C \mathrm{IB}$, is present

THEN $(20,1)$ suggestive morphology if igneous rocks, SitR $(0.03), "$

where RCIB is the evidence, SIIR is the hypothesis, $(20$ and 1) are the values of likelihood sufficiency (LS) and necossity ( $L N)$, respectively, associated with presence and absence of the evidence, and $(0.03)$ is the prior probability associated with the hypothesis SMIR (Gasehnig, 1982, p. 51, Fio. 3.1).

reduce the processing steps required for a solution. In contrast, an algorithmic rule would be rigidly applied and many iterations carried out before a solution is reached. Another method of representing knowledge is based on "frames," in which features are associated with nodes representing concepts or objects that can be organized into a hierarchy (ifaterman, 1986). Each node has associated attributes and values that can be automatically inherited elsewhere in the hierarchy. Semantic and taxonomic notworks, which store an organized set of names representing objects or relations, may also be used to simplify the description of facts. In practice, an inference network is a special instance of a semantic net work.

The inference engine mav reason in several ways, according to the data supplied to it. It can proceed from one rule to the next, continually updating its understanding, until it is able to make a decision. In one case, it may be given some facts, then search for a combination of them in agreement with a priori specifications in order to establish a hypothesis. This is ealled "forward chaining" or "data-driven search." In the other case, a hypothesis or model is first defined, then the supporting rules, and finally the supporting facts are arrived at. "This is called "backward chaining" or "goal-driven search." Most expert systems covered in this survey were either backward chaining or forward chainine. Only a few have the capabilities to handle both types of inferencing.

An important ability of many expert systems is that of accepting evidence that has some degree of uncertainty attached to it. This involves the use of probability measures, certainty factors or likelihood measures, such as those shown in rule $V$ of Table 1. This example is taken from PROSPECTOR, where geological reasoning was extensively developed. In this situation, two likelihood measures, LS and LN, are user. They can be modificd during interaction with a user, depending on the certainty of the evidence that the user provides. Certainty is provided as an interger between -5 and +5 , respectively denoting absolute certainty of absence and of presence of the evidence. The two likelihood measures are modified by this interaction before the rule is activated towards the hypothesis connected to it in the inference network. This modifies the a priori probability for the hypothesis.

For example, as deseribed by Duda and others (1979) for PrOSPEC lOR, and shown in Figure 1 , the definite presence of the evidence RCIB multiplies the "odds" of SMIR by a factor 20, raising its probability from 0.03 to 0.382 . Here $R C I B$ is the abbreviation for evidence of the presence of intrusive breccias, and S.IIR is the abbreviation for the hypothesis suggestive morphology of igneous rocks. The prior odds on S $111 R$ are $0.03 /(1-0.03)=0.030927$, giving posterior odds on SMIR equal to $20 * 0.030927=0.61855$ $(1 * 0.030927=0.030927$ for the observed absence), which corresponds to a probability of $0.61855 /(1+0.61855)=0.382$ $(0.030927 /(1+0.03927)=0.030$ for the observed absence). Here odds and probability are freely interchangeable through the simple relation $\mathrm{O}=\mathrm{P} /(\mathrm{l}-\mathrm{P})$, where $\mathrm{O}=$ odds, and $\mathrm{P}=$ probability. Hence, $\mathrm{P}=\mathrm{O} /(\mathrm{l}+\mathrm{O})$.

Bayes' rule can be stated as $O(H \mid E)=L S^{*} O(H)$, where $E$ indicates the evidence, $H$ the hypothesis, and LS is the likelihood sufficiency. Often a level of confidence can he associated with the volunteered piece of evidence E'. The level of confidence modifies the a priori probability of the hypothesis H, as well as the other hypotheses in the network, until the goal state is reached. In our example, the goal state is "a porphyry copper deposit is (or is not) present."

\section{A Survey of Expert Systems in Geoscience}

The majority of the papers published in the 1980 s covering AI applications within the geosciences have been deseriptions of expert systems in various stages of completion. An extensive literature search carried out on this topic is represented in Table 2. This describes the geological discipline or subfield covered, and the function and purpose of the expert system.

Table 3 gives further characteristies of each of the $37 \mathrm{ex}-$ pert systems. How is knowledge represented? - production rules, semantic networks or frames? What kind of inference is used in the system - is it a forward or backward chaining system, or a modification of these, and can imprecision and uncertainty in the data be represented? Does the system involve some form of spatial reasoning so that it provides information on the extent of some object or positional property in two or more dimensions? Is there some communication to an external database or conventional software parkage that lies outside the expert system itself? What computer language or shell was used for programming? On which machine does this expert system operate? What was the status of the project at the time that the paper was written or when the sustem designer was contacted? Was AI necessary for solving the problem most effectively? 
EXPERTSYSTEV

RFFERFNCF

GEOLOGICAL ISLCIPLINE

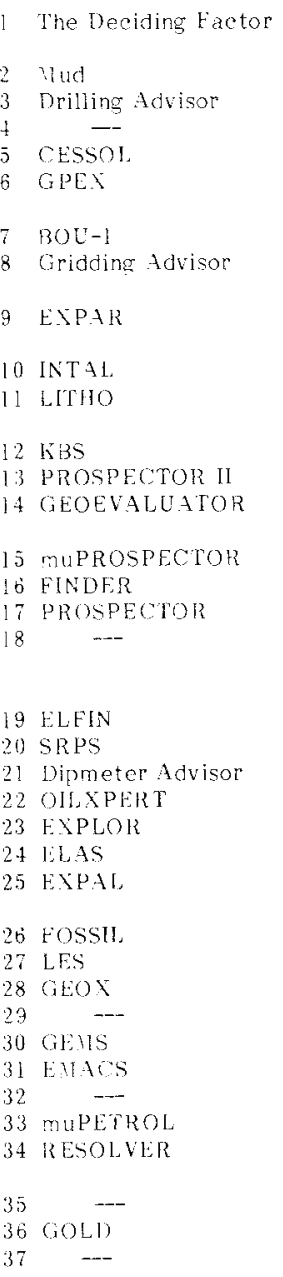

Decision laking Expert Shell

\section{Drilling}

Drilling

Engineering geology

Engineering geology

Geophysical drilling,

minepal exploration

Geostatistics

Gridding of geo-

logical map data

Hytrogeology

Igneous petrology

Log analysis for oil exploration

viner $\log y$

Iineral Exploration

Hineral exploration

Uineral exploration

l?ineral exploration

Sineral exploration

Natural Language

Processing system for cartography

Oil exploration

Oil exploration

Oil exploration

Oil exploration

Oil exploration

Cil exploration

paleontology and

Paleontology Identification

Photointerpretation

Remote sensing

icmote sensing

lemote sensing

Reserve estimation

Sedimentology

Sedimentology

Seismic

interpretation

Seismology

Spectroradiometr

Volcanology

Planning

Interpretation

Advisor

Advisop

Identification

Interpretation

Identification

Prediction

Identification

Parser

Prediction

Interpretation

Interpretation

Prediction

Advisor

dentification

Interpretation

Interpretation

Prediction

lientification

Identification

Identification

dentification database management

Diagnosis and Debugging Diagnosis and j) ebugging

Identification Planning

Interpretation, Planning

Prediction, Simulation

Identification, Prediction

Interpretation, Prediction

Indentification

Image Interpretrtion

Image Interpretation

Liu, 198.5

Lister et al., 1987

Rosenthal-Sabroux et al.

1984

Prediction, Planning
EL'NGIION

Identification

mainframe computers, and only five were built on symbolic workstations. Many of those developed in the past two or three years have been based on small, inexpensive micro-computers; 16 were PC-based.

Systems that appeared to be proposals rather than working systems were labelled as such in the "Status of Project" section of Table 3. If an expert system successfully accomplished the tasks it was designed to achicve, it was labelled as "completed" in the table, although it was not clear to what extent this mas true. Systems beyond the proposal stage, which did not yet accomplish their intended tasks, were labelled as "partially completed." Only 15 systems could be labelled "completed," according to these criteria.

Tables 2 and 3 show that not all expert systems can accept imprecise or uncertain data. Spatially distributed information, including remotely sensed and other map data, is being examined at various levels of sophistication. In many cases, AI components constitute only part of a computer program, acting as intelligent interfaces to more conventional algorithms or databases. In 23 expert systems out of the original 37 , the usage of AI was confirmed as being necessary. Table 4 summarizes the most important characteristics of some representative expert systems.

\section{PROSPECTOR}

Probably the best-known expert system in geology is PROSPECTOR, a program to assist in mineral exploration (Duda, 1980). In this system the reasoning process of an experienced geologist is emulated to evaluate the

The geoseience disciplines covered include such diverse areas as nineralogy, paleontology, remote sensing, volcanology, engineering geology and geostatistics but most (17) deal with petroleum geology and mineral exploration. Most applications can be grouped into identification, interpretation, advising, prediction, planning, or diagnosis/debugging. The systems performing identification and interpretation tasks accept as inputs physical observations from hand specimens, field surveys and laboratory tests. The advising systems guide the user through the manipulation of a conventional softuare packase. Prediction systems attempt to locate and estimate the extent of oil and mineral deposits. Planning systems design programs for preventive or exploratory measurements. The diagnosis-debugging systems are all related to trouble-shooting of trilling technology problems.

By far, the largest number of expert systems surveyed are based on explicit production rules, and nine are capable of spatial reasoning. Twenty-two of the expert systems were based on a symbolic programming language such as some variant of LISP or PROLOG, or based on expert shells such as EMYCIN, OPS5 or KS3000. Apparently, a symbolic programming language is not a prerequisite for an operational expert system.

Export systems developed in the early part of this decade were based on relatively large minicomputer systems such as the VAX. Nine of the surveyed systems were based on likelihood that a mineral prospect or region resembles one or more models built into the knowledge base. Several ore deposit models have been encoded, which reached different degrees of development in terms of their sematic networks, descriptive text and testing.

Inference, semantic and taxonomje networks were used in PROSPECTOR, the inference network that was described earlier. As shown in Figure 2, logical, plausible and context relations were distinguished in the reasoning processes represented in the net: orks (Gaschnig, 1982). To facilitate the building of the models and of the different networks, a knowledge acquisition system (KAS) containing an editor (RENE) was programed by Reboh (1981) as an empty shell for general purpose knowledge engineering.

A user provides information about a prospective geological site including the type of terrain, mineralogy, geographical location or structure. The program compares these inputs with the built-in models in its database. After prompting the user for more information, it makes a report on the type of minorial deposit that it assesses to be present, plus a degree of confidence associated with this conclusion. West (1985) cautions, however, that there are two major disadvantages to numerical methods for establishing measures of confidence such as that of PROSPECTOR. First, experts in the particular field may find it difficult to provide figures for measures such as the prior probability, LS and LN, because the applications themselves are imprecise. Second, 
experiments have demonstrated that the behaviour of such systems may be "... sensitive to perturbations up to 30 号 in selected values."

In the interactive mode, PROSPECTOR provides on-line consultation. Two other kinds of operation have been programmed: a batch mode to process data from questionnaires and for model-performance testing, and a graphic input/ output mode whereby maps are placed on a graphic tablet digitizer to obtain digital contour maps. Such maps provide spatially distributed evidence for "drilling-site-selection" models for which field and map evidence are combined (Duda et al., 1978, Duda, 1980). An image processing system produces and shares digital image files, of up to $128 \times 128$ pixels or cells, with PROSPECTOR. These files, evaluated by the inference network, produce a simplified digital map of a prospective area. Elementary spatial reasoning is built into the drilling-site-selection models by rating cells according to their linear distance from contours or traces of fractures (Duda et al., 1978). Unfortunately, no action followed the experiments on drilling-siteselection models of 1979.

\section{PROSPECTOR-Based Systems}

PROSPECTOR II, currently under development (McCammon, 1987), differs from PROSPECTOK in two significant ways. First, it uses frames to represent "rules," which simplify model building and permit the easy management of a large number of models. One example is shown in the "bitmap window" in the upper right portion of Figure 3 (see inset $\mathrm{A}$ ). The second difference between the two systems is that the volunteer mode of

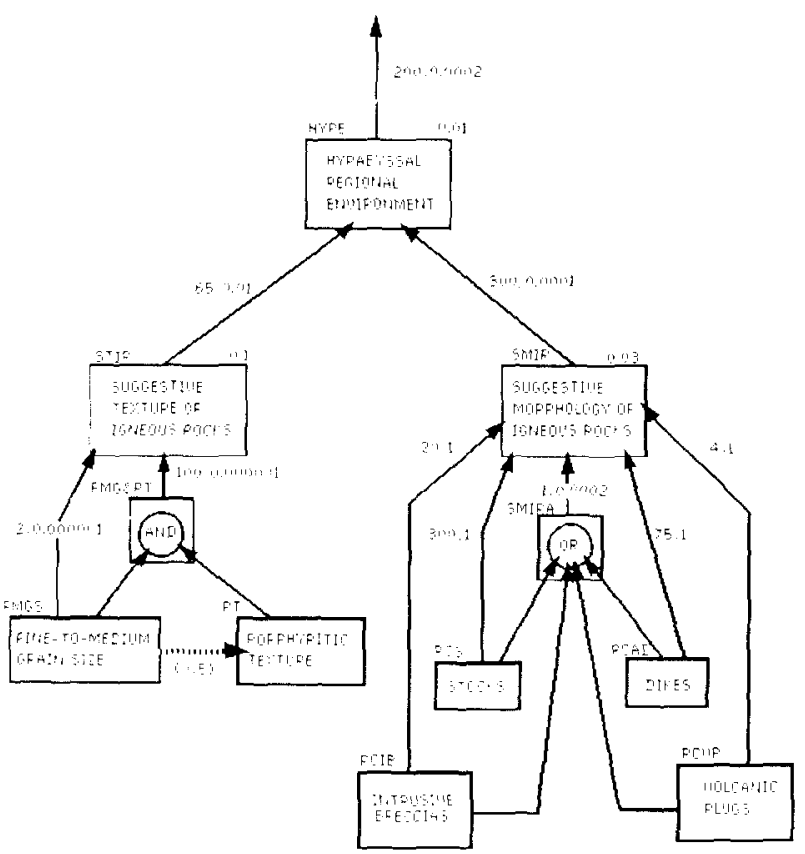

is mUPROSPECTOR

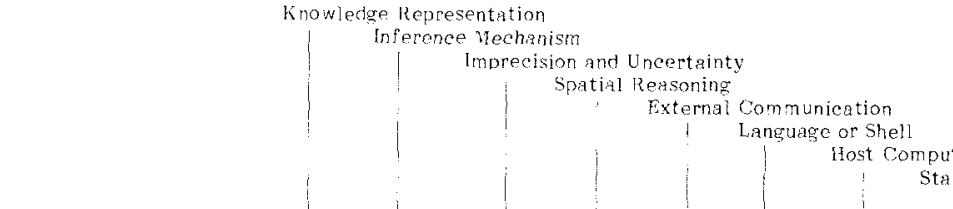

tatus of System

Was Al Necossary?

l DECIOING FACTOR

$2 \quad 410$

3 DRILING ADVISOR

5 CESSOL

G GES

8 GRIDDING ADVISOR

9 EXPAR

id INTAL

0 INTA

3 PROSPECTOR II

4 GEOEVALUTOH

16 FINDER

17 PROSPECTOR

18 EITEIN

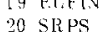

21 DIPYTETER ADVISOR

22 OLIXPER'T

23 FXPLO!

24 the

25 EYPAI.

26 Fossi:

28 OFOX

28
29

30 GENIS

31 EXTACS

32 mए PE TRO

34 RESOLVER

$35 \quad-$

$36 \mathrm{GOL} \mathrm{D}$

$\mathrm{FC} \quad \mathrm{YE}$

$?$

$\mathrm{BC} F$

$\mathrm{FC}$

$\mathrm{BC}$

Y

$\mathrm{KS} \quad \mathrm{YES}$

$\mathrm{BC}$

$Y E S$

BEFC YES

BC.

$B C F C$ YES

?

FC YLS YES

FC:

EC? $\quad Y$

FC

$?$

? ? ?

13C

FC: $33 \mathrm{C}$

$\mathrm{BC} Y \mathrm{YES}$

BC YES

$13 C$

FC YAS

ins

$\begin{array}{ll}\text { PAS } & P C \\ \text { OPS5 } & \text { SA } \\ \text { KS3+S1 } & \text { SH } \\ \text { PR } & P C \\ \text { PSP } & \text { PC }\end{array}$

CH WU

CH TES

cy

PCII Y

PCAI YES
PCYT YES

C.I

CW YES

CH YES

PCH Y Y

PCH :

का Y

PCh

PR? YES

$\mathrm{Cll}$ YES

CW YES

PR ?

M $\mathrm{YH}$

PCs

? YES

PCI YES

PCAT YES

PCA YES

PC Y Y

CM YLS

PCH YES

?

$R$
$R$
$R$
$R$
$R$
$R$
$R E$
$R$
$R$
$R$
$R$
$R$
$R$
$F 1 S$
$R$
$R I$
$R$
$R I S$
$N / A$
$R$
$R$
$R$
$R$
$R$
$R$
$R$
$F$
$R$
$R$
$R$
$R$
$R$
$R$
$R I$
$R I$
$R$
$R$
$R I S$
$R$

FC YES

ANGWA YECIANISY: $\mathrm{BC}$ = backward chaining, $\mathrm{FC}=$ forward chaining, $\mathrm{KS}$ = keyword search

THE OR SHELL: $M P R=$ microProlog, EHY = EMYCIN, PAS = PASCAL, LSP = LISP, ILSP = INTERLISP, PR

HOSI COMPUTER: PC - microcomputer, $\mathrm{VI}=$ minicomputer, $\mathrm{H} \mathrm{A}=$ mainframe, $\mathrm{SW}=$ symbolie workstation.

STATUS OF PROJKCE: Cil $\approx$ completed, $\mathrm{PCu}=$ partially completed, $\mathrm{PR}=$ proposed.

Information unclear or not available in the literature.

operation in PROSPECTOR II has been expanded to exploit the graphics display capability of the Interlisp-D programming environment. A user can select items that relate to descriptions such as rock type, geologic age, minerals and geochemical elements. Input is interpreted in the same manner as in PROSPECTOR and results are shown in the window in the left centre portion of Figure 3 (inset B). A diagram of a particular model, also shown in Figure 3, is easily retrieved. "The next logical stage of development of PROSPECTOR II is to incorporate spatial data to be interpreted by the system.

Those systems based on PROSPECTOR or variants of it have retained the original inference network. However, only PROSPECTOR II has retained its semantic network. The remaining PlROSPECTOR-based systems (The Deciding Factor, mUPROSPECTOR and MUPETROL) were rewritten for microcomputers. The Deciding Factor contains a sim-

Figure 2: Part of inference network for a hypabyssal (HYPE) porphyry copper deposit model in PROSPECTOR. After Reboh, I981, p. 13, Fig. 3. Logical (AND-OR), plausible (solid arrows) and contextual (dashed arrows) relationships or rules are represented. Inside the boxes are the statements of evidence or hypotheses; above to the left are the abbreviations, and to the right, the values of a priori probabilities. The values of likelihood sufficiency and necessity appear along the solid arrows; the context interval appears below the dashed arfors. 
TABLE 4: Representative Examples of Expert Systems in Geology

\begin{tabular}{ll}
\hline \multicolumn{1}{c}{ Main Characteristics } & Name of System \\
\hline $\begin{array}{ll}\text { Inference, semantic nets, imprecision, } \\
\text { uncertainty (frames). }\end{array}$ & $\begin{array}{l}\text { PROSPECTOR } \\
\text { (PROSPECTOR II) }\end{array}$ \\
$\begin{array}{l}\text { Expert shell for mainframe. } \\
\text { Expert system converted to microcomputer. }\end{array}$ & KAS \\
$\begin{array}{l}\text { Expert shell for microcomputer } \\
\text { (commercial product). }\end{array}$ & The Deciding \\
Search program. & Factor \\
Simulation of search patterns. & INTAL \\
Interface to a geostatistical package. & FINDER \\
Graphic interaction and pattern & BOU-1 \\
recognition (commercial product). & DIPMETER \\
Spatial and temporal reasoning, usage of & ADVISOR \\
metarules, imprecision, uncertainty. & ELFIN
\end{tabular}

plified version of handling uncertainty, derived from PROSPECTOR. It also provides a "friendly" editor for building inference networks with a dendrogram-like structure.

mUPROSPECTOR was developed for a microcomputer using the language muLISP (McCammon, 1983, 1984 and 1986). It was adapted so that others could tailor it to a variety of problems such as mineral endowment estimation (Koch and Papacharalampos, 1988) sedimentary basin analysis (Miller, $1986,1987 \mathrm{a}, \mathrm{b})$, and regional geological environments at the district and outcrop level (McCammon et al., 1984, MeCammon, 1985). muPROSPECTOR enables rules with ternary choices (YES, NO, DON'T KNOW) or multiple choices for which menus are generated. Explanations and facilities for summarizing conclusions are available, which make it relatively easy to store knowledge about events or geological objects. In its simple structure, no provision is made for complex reasoning with uncertainty weighting.

\section{INTAL}

An expert system has been designed by Hawkes (1985) to enable an inexperienced geologist, with a knowledge of common rock-forming minerals, to identify igneous rocks from hand specimens. This process is based on a physical description in English, and the INTAL system is programmed in BASIC and operates on a microcomputer. Best deseribed as a keyword search program, INTAL interactively scans the input for certain keywords relevant to rock identification (such as those relating to crystallinity, grain size and texture) rather than performing as a parsing system. The program has generated some interesting discussions on nomenclature among professional geologists, and it promises to be a useful teaching tool.

\section{FINDER}

The integration of spatial patterns for geochemical samples in mineralized and barren areas was used

Figure 3: The user interface of PROSPECTOR II. The Interlisp-D environment allows one to use overlapping windows. Bitmap at the top right is a listing of the $s_{n}$-greisen model. Below it is a model diagram. A large bitmap on the left is the resulting evaluation. R.B. McCammon, personal communication. by Singer (1985) in designing FINDER, an artificial intelligence program written in PASCAL for a mainframe computer. Target areas are selected by means of geological, geochemical and geophysical variables sampled regularly over a region. The rule-based program uses Bayesian statistics and a powerful area-of-influence method of variously shaped targets with preferred orientation. FINDER provides estimates of the number of deposits for each target shape, size and anisotropy. Results are in the form of contour maps, character plots and tables. A simple interaction with prompts and explanations is used by the program. Singer (1985) commented that although strictly speaking FINDER is not an expert system it employs the principles of AI to simulate spatial patterns given target geometry and the position of samples or drill holes.

\section{DIPMETER ADVISOR}

Of the few commercial expert systems available in geology, perhaps the most complete is the DIPMETER ADVISOR system for well-log interpretation developed at Schlumberger (Smith, 1984). Oil-well logs record measurements made by geophysical tools first lowered into boreholes, then raised out of them. Sequences of values for rock conductivity in different directions, gamma-ray values, resistivity and so forth can soon be integrated with measurements of the inclination and orientation of the tool to estimate the magnitude and azimuth of the dip or tilt of various formation layers penetrated by the boreholes.

This information is combined with knowledge of local geology and measurements from other logs, such as lithology, dip pattern or depositional sequences. Characteristic dip patterns and their connectivity are identified by a pattern recognition procedure through a sophisticated graphic interaction, as shown in Figure 4. A large amount of effort went into developing the user interface, to which $42 \%$ of the programming code is devoted. An example of a rule for this expert system is shown in Table 1.

\section{Some Other Examples}

A promising use of $\mathrm{Al}$ technology has been to provide intelligent interfaces to statistical packages (Gale, 1986). BOU-1 (Dimitrakopoulos, 1987 and Dimitrakopoulos et al.,

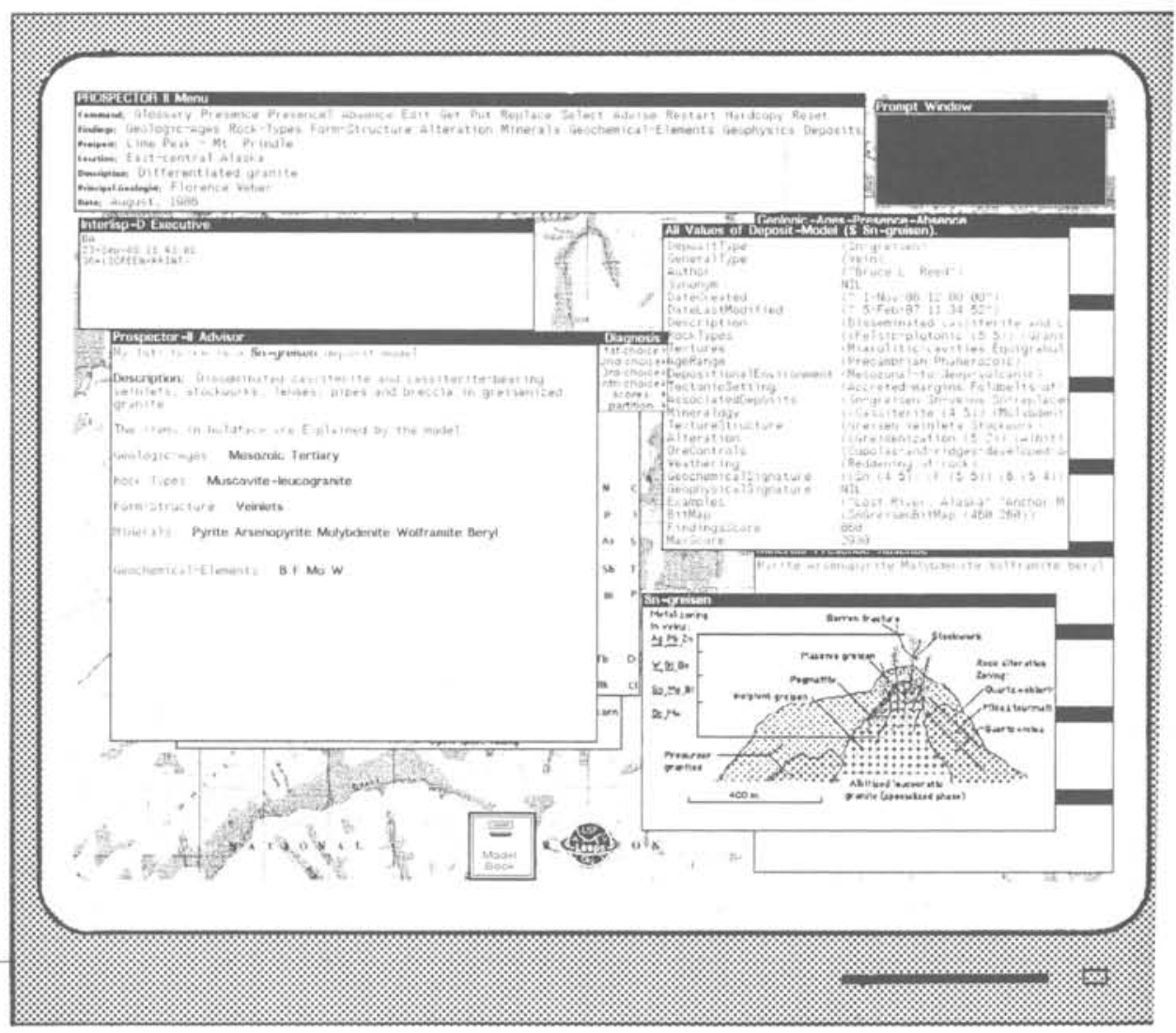


1986) is an intelligent interface to VARIO3, a program for variogram calculation and evaluation of experimental characteristics (Geostat Systems International Inc., 1983). Interaction with the user facilitates the collection of the required data and its transformation into processable form, calls conventional subroutines for calculation of specific values, and outputs results and their interpretation.

Spatial and temporal reasoning, control of reasoning through rules and metarules (rules governing other rules) and approximate reasoning are used in ELFIN (Martin-Clouaire, 1984). This expert system was designed to assist a geologist in the study of hydrocarbon migration from a source rock into a reservoir zone. It is based on principles of possibility theory developed by Zadeh (1978) to take imprecise knowledge into account (Martin-Clouaire and Prade, 1984).

\section{Computer Vision}

Though most computer vision research has been restricted to fields that lie outside of geology, research in this area is worthy of brief mention, because geology is likely to benefit greatly from this field. Computer vision techniques have been used for automatic photo-interpretation and map interpretation systems. Al has been used to represent symbolically visual knowledge and interpret man-made objects from aerial photographs (Shapiro, 1985, Nagao and Matsu-

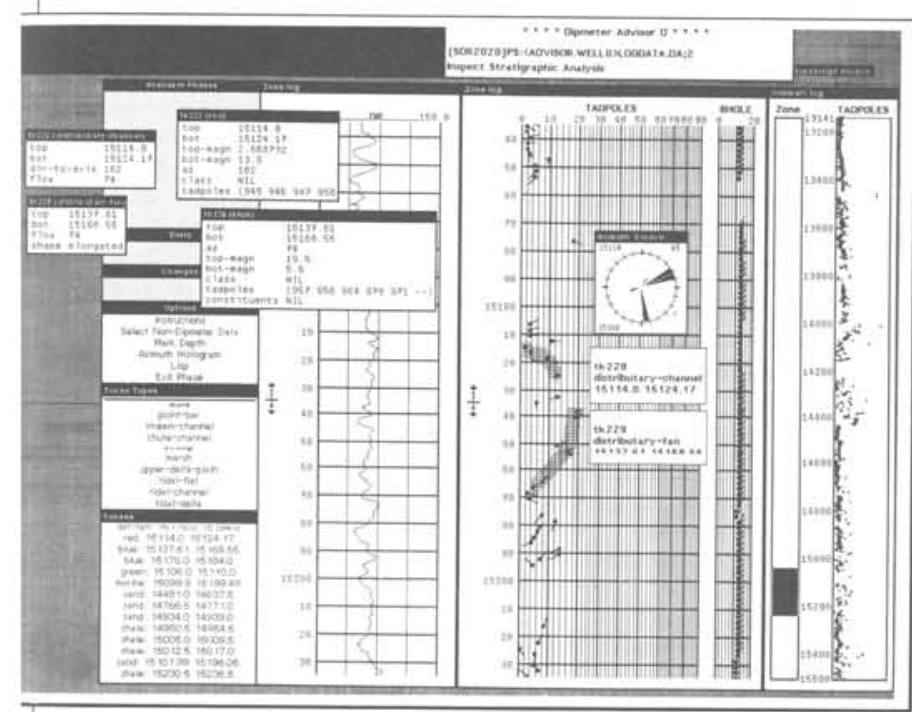

Figure 4: Stratigraphic analysis interaction in the DIPMETER ADVISOR. After Smith, 1984, Fig. 3, p. 4 .

yama, 1980, Matsuyama and Hwang, 1983, and McKeown, 1984). Fabbri and others (1988) have reviewed applications of AI to remote sensing, describing in particular the use of AI techniques in land cover analysis, clear-cut monitoring and image classification. Cartographic and geographic knowledge are also being modelled; Mackworth (1977) and Havens and Mackworth (1983) have developed a program to interpret maps sketched either freehand or on a graphic tablet.

The analysis, interpretation and manipulation of spatially distributed data in geology is still affected by the complexity of spatial relationships both in cross sections and in maps or digital images. A technique proposed by Simmons (1982, 1983) termed "imagining," attempts to simulate geological events by reasoning from geological cross sections (see also Simmons and Davis, 1983). Figure 5 shows, on the left, a cross section and a plausible sequence of events to explain the relationships illustrated.

To simulate geometrically a sequence of events, it is necessary to insert reasonable and realistic parameter values in the symbolic sequence (shown in middle illustration). More-

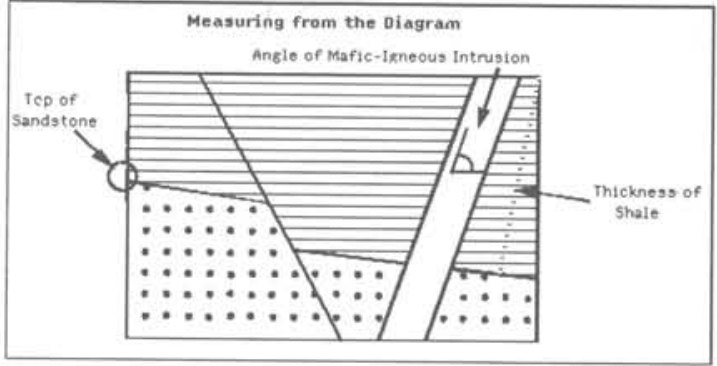

Tspical Geologic Interoretation Problem and Solution

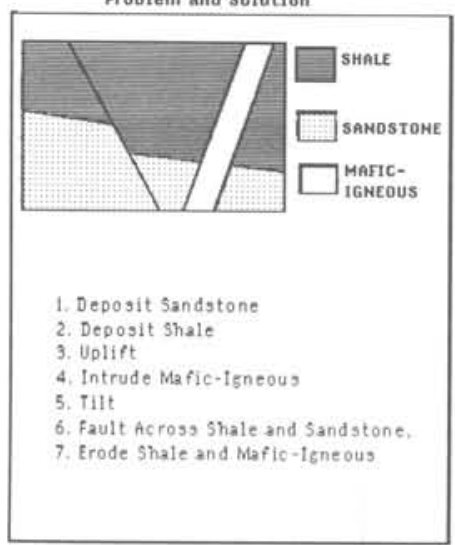

Solution to figure at left with Parametor Values

Deposit Sandstone (to a depth of 450 meters below sea level). neters below sea leveth of 30 3. Uplift (by 200 meters). 4. Intrude ( 80 meters of) MaficIgneous (at an angle of 78 deg. 5. Tilt (by -16 des: 6. Fault (at an angle of 108 deg.) Across Shale and Sandotone. (with a stip of 76 meters). Erode Shale and Mafic-Igneous (to sea-1evel).

Figure 5: "Imagining" in the simulation of geological cross sections. After Simmons, 1983, Figs. 1 to 4. Eor explanation see text.

over, such parameters have to be translated into usable measurements from the same section for which a sequence of events has to be simulated (illustration on right). Both quantitative and qualitative simulations are required to approximate the known cross section; neither simulation alone seems to suffice. Comparisons between a simulated section and the goal (original section) are made to assess the results.

Many geological interpretations and models are based on visual representations such as maps, cross sections, aerial photographs, satellite images, rose diagrams, contour maps and other forms of diagrammatic information, in which spatial characterization is fundamental. Computer vision can provide new tools for automatic spatial reasoning in geology.

\section{The Current Status of AI in the Geosciences}

Research on AI, and particularly expert systems, ran into major problems in 1986 and 1987. Companies attempting to exploit AI techniques, as well as academic institutions working on pure research, have experienced many technical and financial difficulties (Lamb, 1986). The literature covered in this review provides some clues as to why this is so.

Many of these difficulties may be seen as the normal result of unrealistic, even misleading, expectations of what AI has accomplished and what it could achieve in many domains. In some cases, the vendors of expert-system tools are guilty of overrating the power of their products and underestimating the effort required to build a system that will solve real problems (Bobrow et al., 1986). Some of the claims made by AI promoters have fuelled much excitement.

For instance, it is said that high order languages such as LISP and PROLOG make it possible to create, debug and maintain very complex programs. These are especially suited for modelling human intelligence and expertise 
beeause they use symbolic inference and forms of knowledge representation, such as production rules. Martins (1984) stated that, in practice, software development is expensive, takes a very long time and is computationally heavy; the code is generally complex to understand, update and maintain.

It appears that many authors of expert-system proposals do not have a clear idea of what they wish their system to accomplish. A major limitation is the lack of attention given to the user, including level of experience and expectations. Moreover, a disparity often exists between an expert's knowledge formulation and how it is entered into the computer: proper procedures and tools are still needed to translate knowledge into computational form. In most of the expert systems studied here, the knowledge representation is limited to one form, generally rules, a single representation that may not be adequate for complex tasks. Of course, many of the problems observed in the development of expert systems are similar to those encountered in any software development project, such as unclear goals and specifications and lack of proper representation and/or user interface.

What we see as very promising trends in the geosciences for the usage of AI include the use of spatial reasoning, new capabilities to simplify the understanding of complex problems, and procedures and tools to allow a user to organize reasoning. Practically all subdisciplines of geology are involved, and there is the obviously increasing use of microcomputers, both in terms of software and hardware. The availability of advanced AI tools, such as shells and multiple display devices, is also encouraging, as are indications that scientists are more concerned with solving problems than using complicated tools or languages.

The expert systems considered here seem necessary in situations requiring many rules or reasoning steps, particularly if different lines of evidence must be combined to support a hypothesis. Quantitative spatial reasoning, something that is unnatural for humans, is required in the geosciences. Mathematical geology has already contributed much towards the analysis of spatially distributed data through statistical methods such as trend-surface analysis and measures of spatial autocorrelation. These methods should now be extended to the construction of expert systems. What has been accomplished so far in the application of AI in the geosciences is perhaps little in terms of practical results, but the trend is clear. Some reasoning mechanisms can indeed become useful processing tools and perform successfully in well-understood situations of narrow scope.

S.M. Yatabe works at the Petawawa National Forestry Institute (Chalk River, Ontario, Canada K0J 1J0) as part of a research team applying remote sensing to forestry inventories. She has worked as an exploration geologist in Canada and West Germany and as a researcher on $\mathrm{Al}$ and remote sensing at the Canada Centre for Remote Sensing in Ottawa.

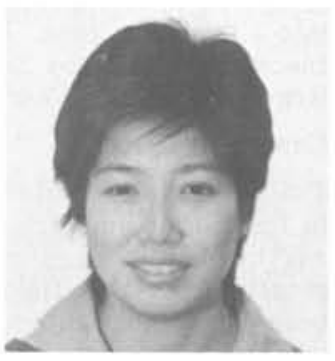

Dr. A.G. Fabbri is a research scientist in geomathematics at the Canada Centre for Remote Sensing (2464 Sheffield Road, Ottawa, Ontario, Canada K1A 0Y7). A former mathematical geologist with the Geological Survey of Canada and senior scientist at the Institute of Marine Geology in Bologna, Italy, he now leads research in digital image processing, the integration of geoscience data and the application of AI to exploration geology.

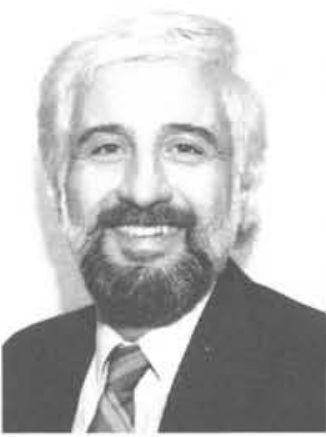

\section{References}

Alexander, L.F., 1985. FOSSIL: an expert system for palneontology. Tertiary Heseareh, v. z, no. $1, \mathrm{p}, 1-11$.

Apté, C.V. and Weiss, S.M., 1985. An approsch to expert control of interactive software systems. Transactions of Pattern Analysis and Machine Intelligence, v. 7, no. 5, P. 586-591. Bobrow, D.G., Mittal, S. and Stefik, M.J., 1986. Expert systemst perils and promise. Communications of the ACM, v. 29, no. 9, p. 880-894.

Bonnet, A., Hary, J., Gannscia, J.G., 1982. L.THO, un système expert inférant la ģéologie de sous-sol. Technique et Science Informatiques, v. I, no. 5, p. 393-402.

Campbell, A and Fitzzerrell, S., 1985. The Deciding Factor user's marual, Software Publishing Corporation, 52p.

Chiou, W.C., 1985. NASA image-based geological expert system development project for hyperspectral image analysis. Applied Opties, v. 25, no. 14, p. 2085-2091.

Conrad, M.A. and Beightol, D.S., 1988. Expert systems identify fossils and nanage large paleontological databases. Geobyto, y. 3, no, 1, p. 42-46.

Dimitrakopoulos, R., 1987. The explicit knowledge formellism as perspective for geostatistical operations. Unpublished Predoctoral Thesis, Ecole Polytechnique, Montreal, p. 46-6!.

Dimitrakopoulos, R., David, M. and Mreotte, D., 1987. The explieit knowledge formalism as perspective for geostatistical operations. Proceedings of 15 th Annual Geochnutauqua, Calgary, Alberth, Oetober 3-4, 1986 (abstract).

Duda, R.O., 1980. The PROSPECTOR System for mineral exploration. SRI Internationat, Final Report, April 1980, $120 \mathrm{p}$.

Duda, R.O., Hart, P.E., Barrett, B., Gaschnig, J.G., Konolige, K., Reboh, R. and Slocum, J. 1978. Development of the PROSPECTOR consultation system for mineral exploration. SRI International, Final Report covering Oetober I, 1976 to September 30, 1978, 193p.

Duda, R.O., Gasehnig, J.G. and Hart, P., 1979. Model design in the ProsPECTOR consultant system for mineral exploration, In: Michles. D. fech. Expert Systens in the

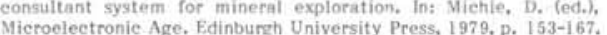

Ennis, S.P., 1985. A look at knowledge-based information systems. Requesting maps fror computers in geologic terms, solution or problem? Geobyte, v. 1, no. 1, p. 24-29.

Ericksor, W.K, and Likens, W.C., 1984. An application of expert systems technology to remotely sensed image analysis. Proceedings. IEEE IX Pecora Symposium on Spatial Ter Remote Sensing Today and Tomorrow, Oetoher 2-4, 1984 Sioux Falls, South Dakota, p. 258-277.

Fabtori, A.G., Fung, K.B. and Yatabe, S.M., 1988. The usage of artifieial intelligence in remote sensing: a review of applications and eurrent researeh. In: Chung, C.F., Fabbri, A.G. and Sinfing-Larsen, R. (eds.), Quantitative Analysis of Mineral and Energy Resources. D. Reidel Publishing Co., Dordrecht, p. 489-512.

Fang, J.H., Shultz, A.W. and Chen, H.C., 1986. Expert systems and petroleum exploration: in overvicw, Geobyte, v, I, no, 1, p, 6-11.
Fowler, M.L., 1987, SR PS; a knowledge-hased system for predieting source rock potential. Geobyte, v. 2, no. 4, p. 24-30.

Gale, W.A., (ed.), 1986. Artificial intelligence and statistics. Addison-Wesley, Reading, Massachusetts, $418 \mathrm{p}$.

Gaschnig, J.G., 1982. PROSPECTOR: An expert system for mineral exploration. In: Michie, D. (ed.), Introductory Readings in Expert Systems. Gordon and Breach Seience Publishers, New York, p. 47-64.

Geostat Systeras International Inc., 1983. VAR103, a program to compute experimental variogram of several variables, User's Guide, Version V2,4, Montreal.

Gero, J.S., 1985. Expert systerns in design and annlysis, National Engineering Conference: The Community and Teehnology - Growing Together Through Engineering, Melbourne, Australia, January 1985, p. 211-217.

Goodenough, D.G., Goldberg, M., Plukett, G. and Zelek, J., 1987. An expert system for remote sensing. IEEE Transactions on Geoseience and Remote Sensing, v. GE-25, no. 3, p. 349-359.

Havons, W.S, and Mackworth, A,K., 1983, Representing knowledges of the visual worid, IEEF Computer, v, 16, p, 90-98.

Ifawkes, D.D., 1985. INTAL - An expert system for the identification of igneous rocks in the hand specimen. Geological Journal, v. 20, no. 4, p. 367-375.

Jannkiraman, C., 1986. A knowledge-based consultant for zeostatistical ore reserve estimation. Proceedings of 1986 Canadian Institute of Mining and Metallurgy Symposium. p. 375 .

Kahn, G. and MeDermott, J., 1984. The MUD system. Proceedings of the First Conference on Artificial Intelligence Applications. IEEE Computer Society, December 1984. p. 116-122. Koch, G.S., Jr. and Papacharalampos, D., 1988. GEOVALUATOR, An expert system for resource appraisalt A demonstration prototype for kaolin in Georgia, U.S.A. In: Chung, C.F., Fabbri, A.G. and Sinding-Larsen, R. (eds.), Quantitative Analysis of Mineral and Energy Resources. D. Reidel Publishing Co, Dordrecht, p. 513-527.

Krystinik, K.B., 1985. An example expert system for the interpretation of depositional environments. U.S. Geological Survey, Open File Report 85-30, 14p.

Krystinik, K.B., 1986. An expert system for identification of foreshore depositional environments. U.S. Geological Survey, Open File Report 86-513, 13p.

Lamb, J., 1986. Expert systems: the bubble bursts. New Scientists, 25 December 1986/1 January $1987,4,112, \mathrm{no}, 1540 / 1541, \mathrm{p}, 30$.

Laurent, J.-P, and J.-P. Mougin, 1984. The application of an expert system to geotechnies for specification of site investigations for buildings: the CESSOL expert system. Seiences ge ia Terre, Serie Informatique Geologique, no. 20, pt. I. p. 69-83.

Lister, R.A., Ali, K., Budn, R., Horsfall, C. and Buntine, W., 1987. GOLD: an expert system for mineral identification from reflectance spectra. Proceedings Austrailian Joint Artificial intelligence Conference, Sydney, November 1987, (Preprint) $15 \mathrm{p}$.

Liu, H.H., 1985. A rule-based system for nutomatic seismic discrimination. Pattern Recognition, v. 18, no. 6, p. 459-463. 


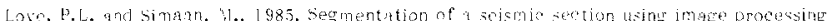
and artifinin intelligenee teehmiques. Pat teen Recoggition, $\because, 18$, no, h, p. $409-419$.

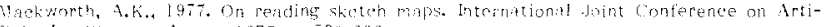
fieial Interligence, August 1977, p. $598-600$.

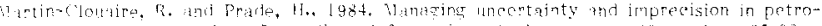

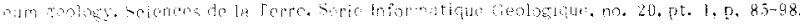

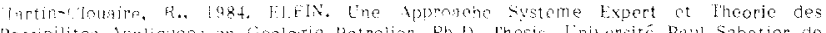

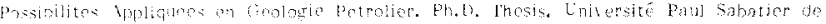

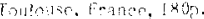

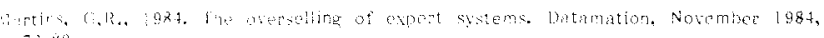
$-i-x i$

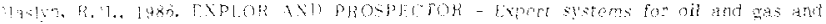

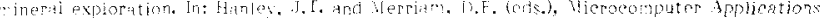

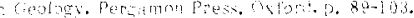

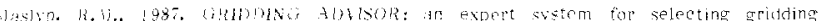

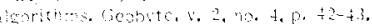

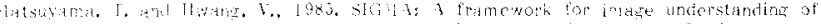

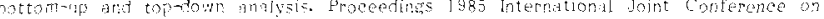

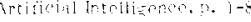

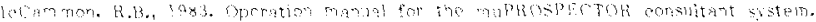
S. Coptorical burley

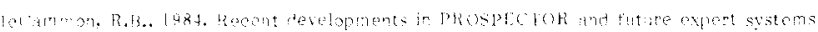

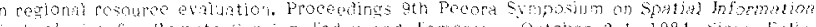

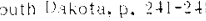

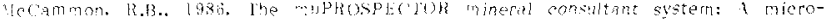
conputer-based expert słstem tor regional cesouree cratuntion. U.S. Geological survey Itulletin $169 \%$, $35 \mathrm{p}$.

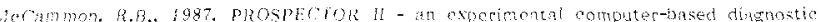

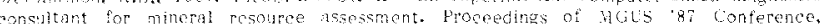

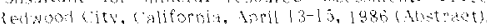

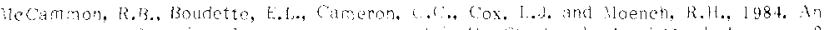

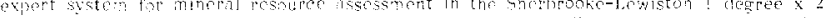

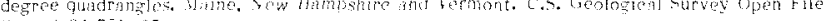
ifport $81-73$ is, 37 .

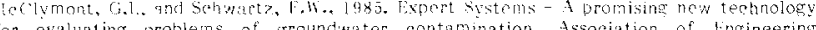

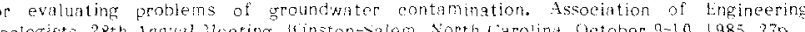

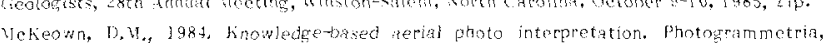
39, no. 3 , p. $91-123$.

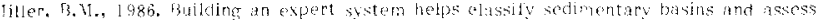
petroleum resources. CEOBYTE, 5.1, no. 2, 2. 14-48, 83-84

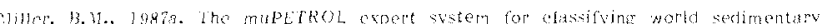
basirs. U.C. Cienlogical survey bulletin 1813,8 is.

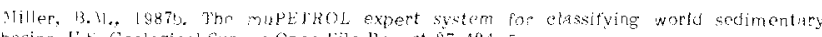
mains. C.S. Geolozical survey open file Report 87-404, 5p.

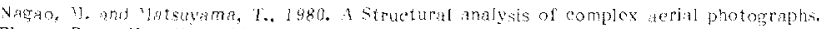
Plenum Press, New York, 1990

papacharalaripos, 1). 1988. GEus: a microconputer-based expert systron for digitul image

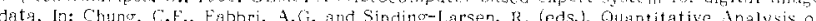
Whierat and Eneros Resourens, O. Reidel Publishing Co., Wordrecht, p. 529-542.

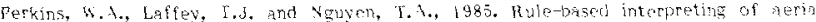

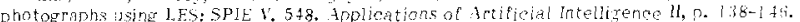

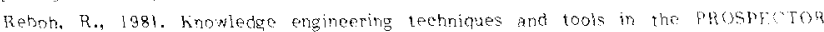
environmert. SRl Intermational. Technicul Note 243 , June $1981,149 \mathrm{p}$

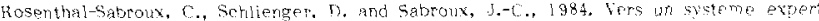
rofeanologue. Sciences de la Tere, scrie In formattigue ceologigue, p. 99-1]2.

Shapiro, L.C., 1985. The role of 31 in computar vistor broeedings of the art conference

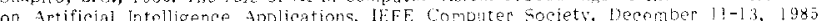
Jiatai Beach, Florida, p. $76-81$.

Simmons, R.t., 1982. Spatial and tempopal reasoning in geologic map intrmpretation. Procecdings of the National Conference on Artificial inteligence, Pittsburgh, Pennsyt vanta, August $18-21,1982$, p. $152-157$.

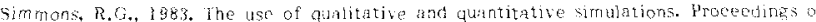

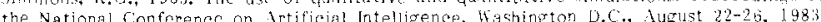
set-368.

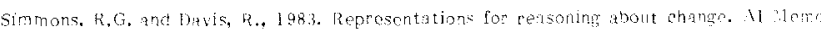
No. 702 . Massachusetts Institute of Technohgy, 54p.

Singer, D.A. Las. Preliminary version of FlNDER, a Pagcal nomeram for lopating minera deposits with spatial information. C.S. Gecological Survey open Filc Report 85-590, $24 \mathrm{p}$.

Smith, B.J., Salctien, L. and Rockel, E., 1986. CPEX: Geophysical Expert System. Canidian Industrial Compurn Sustems Conference, Ecole Polytechnigun, $11 \mathrm{ny} 28-30,1986$, Wontreal Quebec, p. $76-1-16-8$

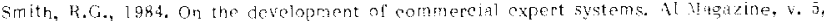
no. 3, p. $81-i 7$.

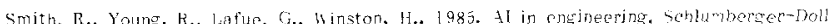
Researen Note, 5 .

Wateman. D. 1. 1987. A guide to expert systems. Addison-Hosley Publishing Company. Refing, Hassachusetts, 41 ap.

llest, 1., 1985 , Toward en expert system for ifentitieation of mincruls in thin soetion. Mathematical Geology, $v, 17$, no. 7, p. 743-753.

Yatabe. S.M. and Fabbri, A.ch, 1988. Artificial Intelligerce in the geoseinnces: a review. In: Rover, J.S. \{erd.\}, Kenmathematical and Statistical Analysis applied to Time Deperdent Data. Scieners de lat Terre, Serie Informatique Genlogique, no. 27, v. 1, p. 37-68. Zadeh, L..., 1978. Fuzzy sets as a basis for a theory of possibility. F'uzzy Sets and Systerms, v. 1, no. $1,0,3-28$

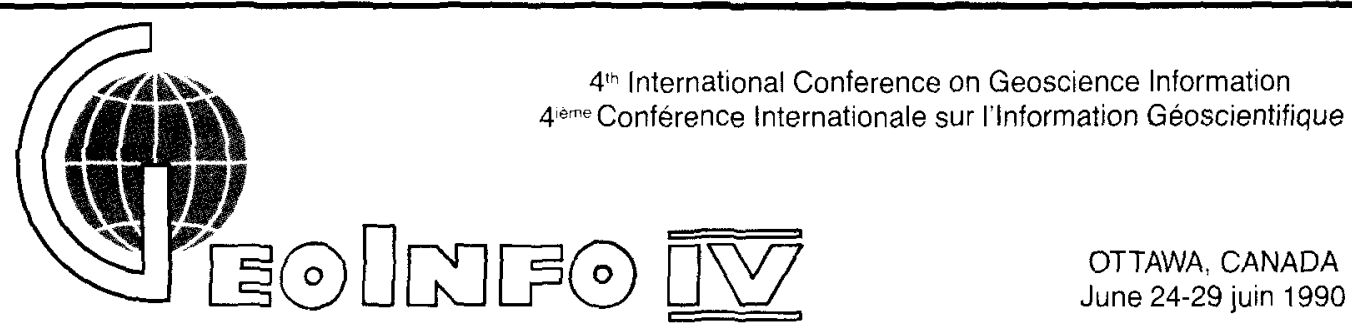

GeoInfo IV will be hosted by the Geological Survey of Canada. Building on three previous conferences (London, England, 1978; Golden, Colorado, 1982; Adelaide, Australia, 1986), Geolnfo IV is aimed at stimulating the exchange of ideas, experiences and data among geoscientists and other professionals involved in the collection, management and dissemination of information in the earth sciences.

The five key themes of Geolnfo IV will be:

- Placing a value on information

- Information handling with digital and analog systems

- Database construction and management

- Managing collections and archives: conservation and preservation

- Strategies for improving the flow of information: in-house, nationally, internationally.

Geolnfo IV will include plenary sessions and concurrent workshops, seminars, posters and discussion sessions. There will also be demonstrations, hands-on sessions, exhibits, visits to local insitutions working in the field of information sciences, and geological field-trips.

Co-sponsors of the conference include the International Union of Geological Sciences, the Geoscience Information Society, the Australian Geoscience Information Association and the Geological Information Group of the Geological Society of London. Further information is available from:

David Reade

Geolnfo IV Secretary-Treasurer

Geological Survey of Canada

601 Booth Street

Ottawa, Canada K1 A 0E8

$\begin{array}{ll}\text { Telephone: } & \text { (613) 992-9550 } \\ \text { Telex: 0533117 EMAR-OTT } \\ \text { Telefax: } & \text { (613) 996-9990 }\end{array}$

